\title{
Analysis of bailout procedure in laparoscopic cholecystectomy for acute cholecystitis
}

\section{Shigeyuki Nagata}

Nakatsu Municipal Hospital

\section{Seiichiro Kai}

Nakatsu Municipal Hospital

\section{Daisuke Korenaga}

Nakatsu Municipal Hospital

\section{Masaki Mori}

Kyushu University

Satoshi Toyota ( $\sim$ satoyota27@gmail.com )

Nakatsu Municipal Hospital

Hiroyuki Orita

Nakatsu Municipal Hospital

\section{Research Article}

Keywords: acute cholecystitis, bailout procedure, laparoscopic cholecystectomy

Posted Date: March 3rd, 2021

DOI: https://doi.org/10.21203/rs.3.rs-257094/v1

License: (c) (1) This work is licensed under a Creative Commons Attribution 4.0 International License. Read Full License 


\section{Abstract}

Background: The Tokyo Guidelines 2018 recommend a bailout procedure consisting of fundus-first cholecystectomy, subtotal cholecystectomy, or open conversion to prevent serious complications in cases of difficult laparoscopic cholecystectomy (LC).

Methods: The hospital records of patients with acute cholecystitis who underwent LC from October 2014 to April 2019 were retrospectively analyzed. The clinical data were compared between the standard and bailout groups. A subgroup analysis was performed to compare the fundus-first and subtotal cholecystectomy techniques versus open conversion.

Results: In total, 160 of 416 Japanese patients who underwent LC were diagnosed with acute cholecystitis. Standard LC was performed in 125 (78\%) patients, and a bailout procedure was performed in $35(22 \%)$. The duration from onset to surgery was significantly longer $(P=0.04)$ and the $C$-reactive protein (CRP) concentration was significantly higher $(P=0.001)$ in the bailout than standard group. The surgical outcomes were worse in the bailout group. In the multivariate analysis, a high CRP concentration at diagnosis was an independent predictor of bailout $(P=0.004)$. In the subgroup analysis, the open group had a significantly longer duration from onset to surgery $(P=0.04)$ and a significantly higher incidence of preoperative drainage $(P=0.002)$. With respect to surgical outcomes, the open group had significantly greater blood loss $(P=0.02)$ and longer hospital stays $(P=0.002)$.

Conclusion: A high CRP concentration is a risk factor for a bailout procedure. Early LC should be performed for patients with acute cholecystitis and a high CRP concentration.

\section{Background}

Improvements in surgical devices and techniques have led to an increase in the use of laparoscopic cholecystectomy (LC) to treat acute cholecystitis (AC). However, bile duct injury (BDI), a life-threatening complication, has also been increasingly reported ${ }^{1,2,3}$. Strasberg et al. ${ }^{4}$ introduced the critical view of safety (CVS), which is formed by Calot's triangle and the cystic duct, to avoid BDI. The CVS is now applied worldwide ${ }^{5,6}$. However, it is difficult to establish the CVS in patients with severe inflammation or adhesion after AC. The Tokyo Guidelines 2018 (TG18) recommend a bailout procedure consisting of the fundus-first approach, subtotal cholecystectomy, or open conversion to prevent BDI when the CVS cannot be secured ${ }^{5}$. However, the bailout procedure is a relatively new concept, and few real-world data have been accumulated. In this single-center retrospective study, we investigated the risk factors for a bailout procedure and performed a subgroup analysis of patients who underwent a bailout procedure.

\section{Methods}

The hospital records of patients who underwent LC from October 2014 to April 2019 were retrospectively investigated. In total, 160 of 416 patients who underwent LC met the diagnostic criteria for AC. These 160 patients were divided into the standard LC group $(n=125)$ and bailout group $(n=35)($ Fig. 1$)$. The 
patients' backgrounds and surgical outcomes such as the operative time, blood loss, postoperative hospital stay, and number of complications were compared between the two groups.

\section{The study protocol is performed in accordance with the relevant guidelines.}

\section{Surgical technique}

All procedures were performed by a surgeon who had performed more than 100 LCs.

\section{Standard LC}

With the patient under general anesthesia and in the supine position, the first umbilical 12-mm camera port was inserted into the preperitoneal cavity, and insufflation pressure of $10 \mathrm{mmHg}$ was used. Three 5$\mathrm{mm}$ ports were inserted from the right hypochondrium and flank. After exposing the CVS at the neck of the gallbladder (GB), the GB artery was cut using a single clip and the cystic duct was cut using a double clip. The whole GB was dissected from the liver bed and removed from the umbilical wound.

\section{Fundus-first cholecystectomy}

Beginning at the fundus (i.e., in a retrograde manner), the GB was separated from the liver without initially visualizing the CVS.

\section{Subtotal cholecystectomy}

An incision was made in the GB, the contents were aspirated, as much of the GB wall as possible was removed, and the stump was sutured.

\section{Open conversion}

An incision was made to connect each 5-mm port hole, and cholecystectomy was performed.

\section{Statistical analysis}

All statistical analyses were performed with EZR (Saitama Medical Center, Jichi Medical University, Saitama, Japan), which is a graphical user interface for R (The R Foundation for Statistical Computing, Vienna, Austria). More precisely, it is a modified version of R Commander designed to add statistical functions frequently used in biostatistics. The $\chi^{2}$ test or Fisher's exact test was used to compare categorical variables, and the Mann-Whitney $U$ test was used to evaluate continuous variables. Univariate and multivariate logistic regression analyses were used to identify the risk factors for a bailout procedure. Receiver operating characteristic curves were used to determine the accuracy of the perioperative C-reactive protein (CRP) concentration and duration from onset to surgery, with values expressed as the area under the curve (AUC) with $95 \%$ confidence intervals. A P value of $<0.05$ was considered statistically significant.

\section{Results}


The patients' characteristics and operative outcomes are shown in Table 1. In total, 160 patients with AC were treated by LC. Standard LC was performed in 125 (78\%) patients, and a bailout procedure was performed in 35 (22\%) patients. There were no significant differences in age, sex, body mass index (BMI), incidence of preoperative drainage, white blood cell (WBC) count, or Charlson comorbidity index between the two groups. The duration from onset to surgery was significantly longer in the bailout group than in the standard group ( $39.7 \pm 40.5$ vs. $28.2 \pm 46.8$ days, respectively; $P=0.04)$. The CRP concentration was significantly higher in the bailout group than in the standard group $(10.47 \pm 9.5 \mathrm{vs} .5 .39 \pm 7.5 \mathrm{mg} / \mathrm{dL}$, respectively; $P=0.001)$. There was no significant difference in the incidence rate of complications, defined as Clavien-Dindo grade $\geq$ II complications. In the bailout group, the operative time was significantly longer ( $206 \pm 61.5 \mathrm{vs} .127 \pm 38.7 \mathrm{~min}, P=0.04)$, the blood loss volume was significantly higher ( $211 \pm 226 \mathrm{vs} .37 \pm 71.8 \mathrm{~mL}, P=0.01)$, and the postoperative hospital stay was significantly longer (7.5 vs. 6.5 days, $P=0.04$ ). 
Table 1

Patients' characteristics

\begin{tabular}{|c|c|c|c|}
\hline Variable & $\begin{array}{l}\text { Standard } \\
(n=125)\end{array}$ & $\begin{array}{l}\text { Bailout } \\
(n=35)\end{array}$ & $P$ value \\
\hline Age, year & $64.9 \pm 15.9$ & $66.4 \pm 15.5$ & 0.66 \\
\hline Sex (male : female) & $11: 5$ & $5: 1$ & 0.56 \\
\hline Body mass index, $\mathrm{kg} / \mathrm{m}^{2}$ & $25.3 \pm 12.2$ & $25.6 \pm 14.2$ & 0.76 \\
\hline Duration from onset to operation & $28.2 \pm 46.8$ & $39.7 \pm 40.5$ & 0.04 \\
\hline Preoperative drainage, $\mathrm{n}$ & $41(32)$ & $17(48)$ & 0.11 \\
\hline $\mathrm{WBC} / \mu \mathrm{g}$ & $11509 \pm 4162$ & $13137 \pm 5795$ & 0.06 \\
\hline CRP mg/dl & $5.39 \pm 7.5$ & $10.47 \pm 9.5$ & 0.001 \\
\hline $\mathrm{CCl}>3, \mathrm{n}$ & 2 & 3 & 0.35 \\
\hline Operative time, $\min$ & $127 \pm 38.7$ & $206 \pm 61.5$ & 0.04 \\
\hline Blood loss, ml & $37 \pm 71.8$ & $211 \pm 266$ & 0.01 \\
\hline Postoperative Hospital stay, day & 6.5 & 7.5 & 0.02 \\
\hline ※Complication, n (\%) & 3 & 1 & 0.45 \\
\hline injure & 1 & 0 & \\
\hline SSI & 2 & 1 & \\
\hline \multicolumn{4}{|c|}{ Data are presented as mean \pm standard deviation, $n$, or $n(\%)$. } \\
\hline \multicolumn{4}{|c|}{$\begin{array}{l}\text { WBC, white blood cells; CRP, C-reactive protein; CCl, Charlson comorbidity index; SSI, surgical site } \\
\text { infection }\end{array}$} \\
\hline \multicolumn{4}{|l|}{$※$ Clavien-Dindo grade $\geq$ II } \\
\hline
\end{tabular}

Next, we performed univariate and multivariate analyses of risk factors for a bailout procedure (Table 2). The cut-off value of age was the median of all patients, and the cut-off value of the BMI was $22 \mathrm{~kg} / \mathrm{m}^{2}$ (the standard value for adults). The cut-off value of the WBC count was 18,000 cells $/ \mu \mathrm{g}$, which is one of the criteria for moderate cholecystitis. A receiver operating characteristic curve analysis showed that the cut-off value of the preoperative duration (onset to surgery) was 35 days (AUC, $0.61 ; 45 \%$ sensitivity, $77 \%$ specificity) (Fig. 2A) and that the cut-off of the preoperative CRP concentration was $9.4 \mathrm{mg} / \mathrm{dL}$ (AUC, 0.66 ; $51 \%$ sensitivity, $80 \%$ specificity) (Fig. 2B). The univariate analysis showed that male sex, preoperative drainage, duration from onset to surgery, WBC count, and CRP concentration were significant 
risk factors. The multivariate analysis showed that a high CRP concentration was an independent risk factor for bailout (odds ratio, 4.16; $95 \%$ confidence interval, $1.56-11.1 ; \mathrm{P}=0.004$ ).

Table 2

Risk factors for bailout $(n=160)$

\begin{tabular}{|c|c|c|c|c|}
\hline \multirow{3}{*}{$\begin{array}{l}\text { Variable } \\
\text { Age }>67 \text { years }\end{array}$} & \multirow{2}{*}{\multicolumn{2}{|c|}{$\begin{array}{l}\text { Univariate analysis } \\
\text { Odd ratio }(95 \% \mathrm{Cl}) \mathrm{P}\end{array}$}} & \multirow{2}{*}{\multicolumn{2}{|c|}{$\begin{array}{l}\text { Multivariate analysis } \\
\text { Odd ratio }(95 \% \mathrm{Cl}) \mathrm{p}\end{array}$}} \\
\hline & & & & \\
\hline & $0.85(0.40-1.81)$ & 0.68 & & \\
\hline Male & $2.38(1.02-5.55)$ & 0.04 & $2.38(1.04-4.56)$ & 0.06 \\
\hline $\mathrm{BMI}>22$ & $0.86(0.75-1.34)$ & 0.50 & & \\
\hline Duration from onset $>35$ day & $2.90(1.33-6.41)$ & 0.04 & $2.1(0.83-5.4)$ & 0.11 \\
\hline Preoperative drainage, $\mathrm{n}$ & $1.93(1.1-4.1)$ & 0.04 & $0.85(0.33-2.2)$ & 0.74 \\
\hline$W B C>18000 / \mu g$ & $2.7(1.17-6.67)$ & 0.01 & $1.29(0.47-3.44)$ & 0.619 \\
\hline $\mathrm{CRP}>9.4 \mathrm{mg} / \mathrm{dl}$ & $5.0(2.22-12.5)$ & 0.001 & $4.16(1.56-11.1)$ & 0.004 \\
\hline
\end{tabular}

We next performed a subgroup analysis and compared fundus-first and subtotal cholecystectomy versus open conversion (Table 3). There was no significant difference in age, sex, BMI, WBC count, or CRP concentration. The duration from onset to surgery was significantly longer in the open group $(63 \pm 48.2$ $v s .30 \pm 33.3, P=0.04$ ), and a significantly higher proportion of patients underwent preoperative drainage in the open group ( $90 \%$ vs. $47 \%, P=0.002)$. In surgical outcomes of each group, there was no significant difference in the operative time or postoperative complications. However, the open group had significantly greater blood loss (388 $\pm 308 \mathrm{vs} .141 \pm 136 \mathrm{~mL}, P=0.02)$ and significantly longer hospital stays (12.7 vs. 7.0 days, $P=0.002)$. 
Table 3

\begin{tabular}{|llll|}
\hline Variable & $\begin{array}{l}\text { Fundus or subtotal } \\
(\mathbf{n}=\mathbf{2 5})\end{array}$ & $\begin{array}{l}\text { Open } \\
(\mathbf{n}=\mathbf{1 0})\end{array}$ & P value \\
\hline Age, year & $64.8 \pm 17.3$ & $70.4 \pm 9.46$ & 0.43 \\
\hline Sex (male : female) & $18: 7$ & $4: 1$ & 1 \\
\hline Body mass index, $\mathrm{kg} / \mathrm{m}^{2}$ & 24.5 & 23.7 & 0.65 \\
\hline Duration from onset to ope & $30 \pm 33.3$ & $63 \pm 48.2$ & 0.04 \\
\hline Preoperative drainage, $\mathrm{n}$ & $8(47 \%)$ & $9(90 \%)$ & 0.002 \\
\hline WBC / $\mu \mathrm{gg}$ & $14032 \pm 5314$ & $10900 \pm 6618$ & 0.06 \\
CRP mg/dl & $11.7 \pm 9.54$ & $7.17 \pm 9.16$ & 0.21 \\
\hline Operative time, min & $199 \pm 60.5$ & $224 \pm 63.6$ & 0.35 \\
\hline Blood loss, ml & $141 \pm 136$ & $388 \pm 308$ & 0.02 \\
\hline Postoperative Hospital stay, day & 7.0 & 12.7 & 0.002 \\
\hline ※Complication, $\mathrm{n}$ (\%) & 1 & 2 & 0.19 \\
\hline injure & 0 & 0 & \\
\hline SSI & 1 & 2 & \\
\hline Data are presented as mean \pm standard deviation, $n$, or $n$ (\%). & \\
\hline WBC, white blood cells; CRP, C-reactive protein; SSI, surgical site infection & \\
\hline ※Clavien-Dindo grade $\geq$ II & & & \\
\hline
\end{tabular}

\section{Discussion}

The present study demonstrated that a high CRP concentration can predict a difficult LC procedure requiring bailout. Some previous studies have also revealed a relationship between a high CRP concentration and open conversion ${ }^{7,8}$. Measurement of the CRP concentration as a predictor is simple and easy to perform. However, CRP is not included in the severity classification of the TG18 ${ }^{9}$; instead, the WBC count is included ${ }^{9}$. This is probably because several studies have demonstrated that the WBC count can predict the life prognosis of patients with $A C$, and the severity classification attaches importance to the life prognosis. Therefore, we believe that predictors of the life prognosis are not the same as predictors of surgical difficulty and that the CRP concentration should be noted as a predictor of difficult 
LC. In our comparison of surgical outcomes, the bailout group showed worse outcomes than the standard LC group, as expected. This may reflect the presence of inflammatory adhesions and postoperative pain. However, there were no significant differences in complications, especially BDI; therefore, we consider that the purpose of the bailout procedures was achieved.

In our subgroup analysis, the open group had poor surgical outcomes (Table 3). Previously, only open conversion was recommended for difficult $\mathrm{LC}^{10}$. However, whether open conversion is really safe remains questionable $11,12,13,14$, and the TG18 recommend other approaches such as fundus-first and subtotal cholecystectomy ${ }^{5}$. Indeed, Kaplan et al. ${ }^{12}$ showed that the incidence of BDI was much higher in open than subtotal cholecystectomy. Several studies reported the efficacy of Fundus first ${ }^{15,16}$ and subtotal approach. Other hands, as for complications of new approach, BDI was reported to increase in case Fundus first was not proceeded along with GB wall ${ }^{17,18}$ and patients underwent Subtotal rarely had recurrence of $A C^{19}$. However, such complications were not observed in our study. Therefor we thought as the TG18 recommendation, not only Open conversion but Fundus first and Subtotal should be performed for difficult LC. To see the patient's backgrounds, the inflammatory level of Open-group was milder instead have much duration from diagnosis to surgery. Previously TG13 recommended delay LC for cases more than 72 hours after the onset because such AC was thought to have severe fibrosis and adhesion and better to calm the inflammation once. However, there was no significantly difference in operation time and occurrence of BDI between early and delay LC by meta-analysis conducted in TG18. It also pointed the demerit of delay LC was recurrence of AC in duration and TG18 was modified as that LC should be performed regardless of the duration from onset ${ }^{20}$. Therefor the many patients in Open group might have repeated recurrences during the duration unknowingly. Those subclinical recurrence may be an another strong risk factor of difficult LC. In this study, the recurrence was not assessed correctly and in any case, it will be better to perform early LC.

This study had two main limitations. First, this was a retrospective observational study with a small sample size. Second, a specific protocol of selecting the bailout procedure was not established, and confounding was not removed in the subgroup analysis.

\section{Conclusion}

In conclusion, a high CRP concentration is a risk factor for a bailout procedure. Early LC should be performed for patients with $\mathrm{AC}$ and a high CRP concentration.

\section{Declarations}

\section{Ethics approval and consent to participate}

This study was conducted in accordance with the Declaration of Helsink, and the protocol was approved by the Ethic Committee of the Nakatsu municipal hospital, Oita Japan. 
Informed consent was obtained from all patients for research purpose.

\section{Consent for publication}

Final approval of the article: All authors

Availability of data and materials: The data that support the findings of this study are available from the corresponding author, upon reasonable request

\section{Competing interests}

The authors declare no conflicts of interest regarding this research.

\section{Funding}

None

\section{Autor contributions}

Writing: ST

Critical review and revision: ST, HO, SN, SK, DK, MM

Final approval of the article: All authors

Acknowledgments: None.

\section{Author's information}

Satoshi Toyota

Department of Surgery and Science

Graduate School of Medical Sciences, Kyushu University

3-1-1 Maidashi, Higashi-ku, Fukuoka 812-8582, Japan

Tel: (+81) 92-642-5466, Fax: (+81) 92-642-5482

E-mail: satoyota27@gmail.com

\section{References}

1. Buddingh KT, Wersma RK, Savenije RA et al. Lower rate of major bile duct injury and increased intraoperative management of common bile duct stones after implementation of routine intraoperative cholangiography. J Am Coll Surg. 2011; 213: 267-274 
2. Pekoji J, Alvarez FA, Palavecino M et al. Intraoperative management and repair of bile duct injuries sustained during 10,123 laparoscopic cholecystectomies in a high volume referral center. J Am Coll Surg. 2013; 216: 894-901

3. Lau WY, Lai EC, Lau SH et al. Management of bile duct injury after laparoscopic cholecystectomy: a review ANZ J Surg 201080: 75-81

4. Strasberg SM, Hertl M, Soper NJ .An analysis of the problem of biliary injury during laparoscopic cholecystectomy. Am J Coll Surg 1995; 180: 101-125

5. Wakabayashi G, Iwashita Y, Hibi T et al. Tokyo Guideline 2018: surgical management of acute cholecystitis: safe steps in laparoscopic cholecystectomy for acute cholecystitis (with videos). $J$ Hepatobiliary Pancreat Sci 2018: 25; 73-86

6. Sanjay P, Kulli C, Polignano FM et al. Optimal surgical technique, use of intra-operative cholangiography $(\mathrm{IOC})$, and management of acute gallbladder disease: The results of a nation-wide survey in the UK and Ireland. Ann R Coll Surg Engl 2010; 92: 302-306

7. Bouassida M, Zribi S et al. C-reactive Protein Is the Best Biomarker to Predict Advanced Acute Cholecystitis and Conversion to Open surgery. A Prospective Cohort Study of 556 cases. J Gastrointest Surg 2019: 25

8. Mok K, Goh Y, Howell L et al. Is C-reactive protein the single most usefulpredictor of difficult laparoscopic cholecystectomy or its conversion? A pilot study. J Minim Access Surg 2016; 12: 26-32

9. Yokoe et al. Tokyo Guidelines 2018: diagnostic criteria and severity grading of ac45ute cholecystitis (with videos) J Hepatobiliary Pancreat Sci 2018; 25: 41-54

10. Yamashita Y, Takada T et al. TG13 surgical management of acute cholecystitis. J Hepatobiliary Pancreat Sci 2013; 20: 89-96.

11. Lengyel $\mathrm{BI}$, Azagury $\mathrm{D}$, Varban $\mathrm{O}$ et al. Laparoscopic cholecystectomy after a quarter century: Why do we still convert? Surg Endsc 2012; 26: 508-513.

12. Kaplan D, Inaba K, Chouliaras K et al. Subtotal cholecystectomy and open total cholecystectomy: Alternatives in complicated cholecystitis. Am Surg 2014; 80: 953-955

13. Borzellino G, Sauerland S, Minicozzi AM et al. Laparoscopic cholecystectomy for severe acute cholecystitis. A meta-analysis of result. Surg Endosc 2008; 22: 8-15

14. Hibi T, Iwashita $Y$, Ohyama T et al. The right way is not always popular: Comparison of surgeon's perception during laparoscopic cholecystectomy for acute cholecystitis among expert from Japn, Korea and Taiwan. J hepatobiliary Pancreat Sci 2017; 24: 24-32

15. Kato K, Matsuda M et al. Laparoscopic cholecystectomy from fundus downward. Surg Laparoscopic Endosc 1994; 4: 373-374

16. Uyama I, lida $S$ et al. Laparoscopic retrograde cholecystectomy fromfundus downward facilitated by lifting the liver bed up to the diaphragm for inflammatory gallbladder. Surg Laparosc Endosc 1995; 5: 431-436 
17. Elshaer M, Gravante $\mathrm{G}$ et al. Subtotal cholecystectomy for difficult LC Uyama I, lida S et al. Laparoscopic retrograde cholecystectomy fromfundus downward facilitated by lifting the liver bed up to the diaphragm for inflammatory gallbladder. Surg Laparosc Endosc 1995; 5: 431-436

18. Strasberg SM, Gouma DJ. Extreme vasculobiliary injuries: ssociation with fundus-down cholecystectomy in severely inflamed gallbladders. HBO Oxford 2012; 14: 1-8

19. Henneman D, da Costa DW, Vrouenraets BC et al. Laparoscopic partial cholecystectomy for sever acute cholecystitis. A meta-analysis of results. Surg Endosc 2013; 27: 351-358

20. Okamoto $\mathrm{K}$ et al. Tokyo guidelines 2018: flowchart for the management of acute cholecystitis. $J$ Hepatobiliary Pancreat Sci 2018; 55-72

\section{Figures}

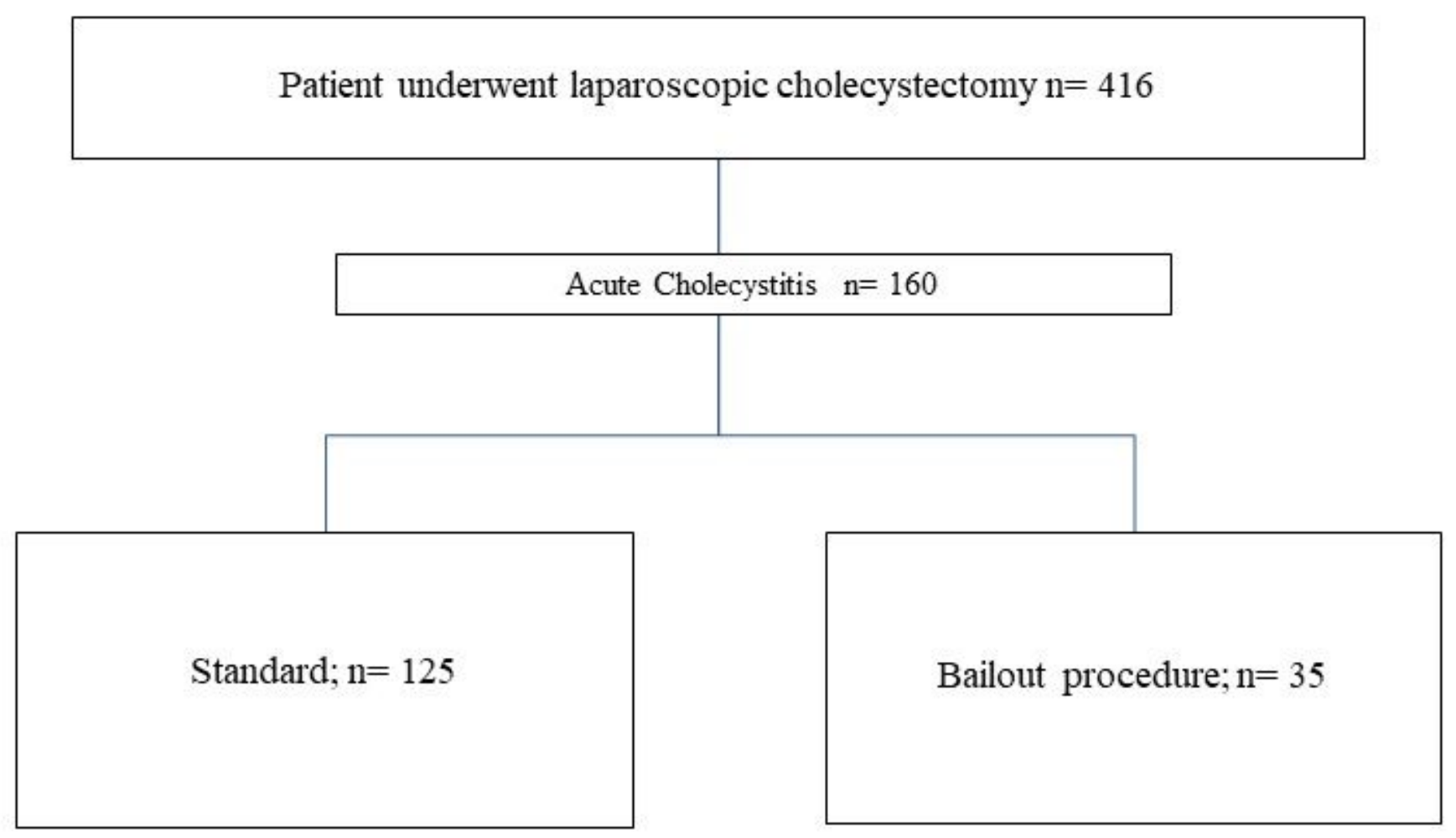

\section{Figure 1}

Flow chart of patient enrollment 

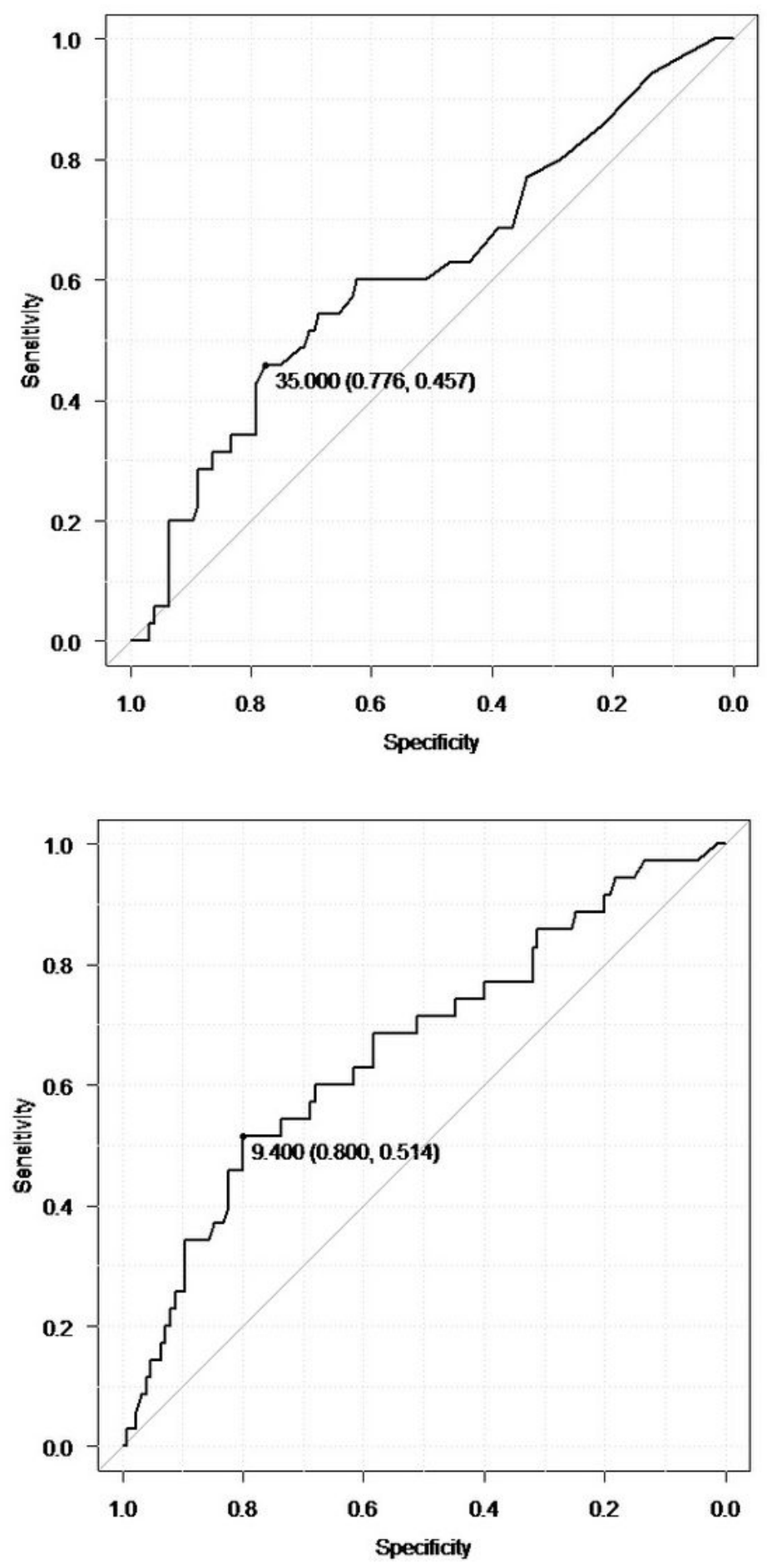

Figure 2

(A) Receiver operating characteristic curve analysis of preoperative duration. (B) Receiver operating characteristic curve analysis of preoperative $\mathrm{C}$-reactive protein concentration. 